\title{
Acute hepatitis after parenteral amiodarone administration
}

\author{
M PYE, R J NORTHCOTE, S M COBBE \\ From the University Department of Medical Cardiology, Royal Infirmary, Glasgow
}

SUMMARY Amiodarone is believed to have caused acute hepatitis 24 hours after intravenous administration in two patients in whom no other alternative cause of hepatitis was found.

Various extracardiac side effects have been reported after amiodarone treatment. ${ }^{2}$ Asymptomatic hepatic dysfunction was reported in $15-40 \%$ of patients on long term amiodarone treatment. ${ }^{3-5}$ These patients had increases in serum concentrations of transaminases of 1.5-4 times normal values.

We report two cases of acute hepatitis that developed 24 hours after intravenous amiodarone treatment. We found no other explanation for the hepatitis in these patients.

\section{Case reports}

\section{PATIENT I}

A 48 year old woman (weight $50 \mathrm{~kg}$ ) had undergone mitral and aortic valve replacement in 1982. She subsequently underwent repeat mitral valve replacement in February 1987. In May 1987 she was admitted as an emergency with a two month history of progressive dyspnoea, nausea, fatigue, and intermittent palpitation. She had been on long term treatment with frusemide, spironolactone, digoxin, and warfarin. On admission her blood pressure was $130 / 70 \mathrm{~mm} \mathrm{Hg}$, the jugular venous pressure was raised $6 \mathrm{~cm}$, and she was peripherally well perfused. The apex beat was displaced and there was a soft apical systolic murmur. There was firm regular hepatomegly (three fingerbreadths). Her electrocardiogram showed atrial fibrillation with a ventricular rate between 140 and 180 beats per minute. Her chest radiograph showed mild cardiomegaly with pulmonary vascular redistribution. Doppler examination confirmed moderate mitral regurgitation and tricuspid regurgitation.

The table shows the laboratory results. On day 1 she was started on verapamil $40 \mathrm{mg}$ three times a day in addition to digoxin. This failed to control the

Requests for reprints to Dr M Pye, Department of Medical Cardiology, Royal Infirmary, Queen Elizabeth Building, 10 Alexandra Parade, Glasgow G31 2ER.

Accepted for publication 14 March 1988
Table Serum concentrations of hepatic enzymes and bilirubin in cases 1 and 2

\begin{tabular}{|c|c|c|c|c|c|}
\hline Day & $A P$ & $A S T$ & $A L T$ & $\boldsymbol{B}$ & $C K$ \\
\hline \multicolumn{6}{|c|}{ Case $1(50 \mathrm{~kg})$} \\
\hline 1 & 145 & 40 & 45 & 34 & 50 \\
\hline 2 & 155 & 35 & 20 & 30 & 60 \\
\hline 3 & 150 & 36 & 22 & 30 & 65 \\
\hline $\begin{array}{l}4 \text { (amiodarone } \\
\text { started) }\end{array}$ & 185 & 40 & 28 & 30 & 70 \\
\hline 5 & 150 & 720 & 580 & 65 & 55 \\
\hline 6 (amiodarone & 140 & 1860 & 1770 & 155 & 50 \\
\hline 7 & 140 & 1010 & 1450 & 145 & 60 \\
\hline 8 & 160 & 320 & 740 & 100 & 60 \\
\hline 10 & 156 & 246 & 700 & 80 & 50 \\
\hline 12 & 170 & 114 & 320 & 55 & 45 \\
\hline 16 & 120 & 37 & 50 & 25 & 50 \\
\hline \multicolumn{6}{|c|}{ Case 2 (54 kg) } \\
\hline 1 am & 200 & 67 & 15 & 10 & 366 \\
\hline pm & 210 & 71 & 27 & 12 & 908 \\
\hline 2 & 240 & 259 & 47 & 15 & 1760 \\
\hline 4 & 250 & 90 & 60 & 12 & 240 \\
\hline 6 (amiodarone & 220 & 45 & 25 & 20 & 100 \\
\hline 7 & 500 & 2400 & 1440 & 60 & 90 \\
\hline 8 (amiodarone & 600 & 2400 & 1600 & 40 & 110 \\
\hline 9 & 500 & 980 & 1340 & 35 & 150 \\
\hline 10 & - & 450 & 770 & 30 & 120 \\
\hline 12 & 250 & 200 & 210 & 30 & 160 \\
\hline 13 operation & & & & & \\
\hline
\end{tabular}

Normal ranges for: AP, alkaline phosphatase (80-280 IU/1); AST, aspartate transaminase (12-48 IU/1); ALT, alanine transaminase (3$55 \mathrm{IU} / \mathrm{l}) ; \mathrm{B}$, bilirubin (3-22 $\mu \mathrm{mol} / \mathrm{l}) ; \mathrm{CK}$, creatine kinase (30-150 IU/1).

ventricular rate and was stopped on day 3. On day $4 \pi$ she still had fast atrial fibrillation despite adequate concentrations of serum digoxin. Treatment with $\omega$ intravenous amiodarone was started. She was given a bolus of $300 \mathrm{mg}$ followed by an infusion of $900 \mathrm{mg}$. On day $5900 \mathrm{mg}$ of amiodarone was given intraven- $\stackrel{\infty}{\rightarrow}$ ously and $400 \mathrm{mg}$ orally and on day $6200 \mathrm{mg}$ was given orally. There was no significant change in her 0 clinical condition despite a considerable rise in the serum concentration of hepatic enzymes. Toxic hepatitis was suspected and amiodarone was stopped. Other treatment was not changed. Serum concentra- 
tions of hepatic enzymes fell 24 hours after amiodarone was stopped. There was no change in her clinical condition. Propranolol $(20 \mathrm{mg}$ three times a day) was started on day 8 and the ventricular rate was rapidly controlled. The patient subsequently underwent mitral valve replacement. Other laboratory tests, including haemoglobin, urea, electrolytes, and erythrocyte sedimentation rate were normal. Hepatitis A and B markers, viral studies, and antitissue antibodies were negative. Blood cultures were sterile.

\section{PATIENT 2}

A 70 year old woman (weight $54 \mathrm{~kg}$ ) was admitted with an acute inferior myocardial infarction. She had a past history of hypertension, angina, hypothyroidism, and polymyalgia rheumatica. She was taking atenolol, nifedipine, prednisolone, and thyroxine on admission. She had clinical and radiological evidence of left ventricular failure, blood pressure was $110 / 60 \mathrm{~mm} \mathrm{Hg}$, jugular venous pressure was elevated $7 \mathrm{~cm}$, and her extremities were cool. The apex beat was displaced and there was auscultatory evidence of mitral regurgitation. There was firm regular hepatomegly (two fingerbreadths). Cardiac catheterisation showed evidence of pulmonary hypertension with a mean pulmonary capillary wedge pressure of $30 \mathrm{~mm} \mathrm{Hg}$, right atrial pressure of $14 \mathrm{~mm} \mathrm{Hg}$, and confirmed gross mitral regurgitation. She was treated initially with intravenous diuretics, sodium nitroprusside, and dobutamine $2.5 \mu \mathrm{g} / \mathrm{kg} /$ $\mathrm{min}$. She remained unwell and on day 5 fast atrial fibrillation developed ( 160 beats/min). Intravenous amiodarone $(300 \mathrm{mg}$ ) was given over 30 minutes, followed by $1200 \mathrm{mg}$ over the next 24 hours. This dose $(1200 \mathrm{mg} /$ day intravenously) was continued until day 8 and then stopped because of an acute increase in the serum concentration of hepatic enzymes and once again a toxic hepatitis was suspected. Serum concentrations of hepatic enzymes fell rapidly when amiodarone was stopped. Her clinical condition remained poor and she underwent mitral valve replacement on day 12 .

\section{Discussion}

Although we cannot exclude an alternative cause of hepatic dysfunction, we believe that the clinical course suggests that amiodarone was responsible for the development of acute hepatitis in these two patients.

Despite clinical evidence of cardiac failure both patients had normal concentrations of serum transaminases before the administration of amiodarone. There was no subsequent deterioration in their condition to account for the sudden increase in serum concentrations of transaminase or bilirubin. The suggestion that amiodarone caused the hepatitis is supported by rapid improvement in their liver func- tion tests when amiodarone was stopped.

The increase in serum transaminases with long term amiodarone treatment was reversible and dose dependent, and did not require withdrawal of the drug. ${ }^{126}$ There have been only two previously reported cases of possible acute hepatitis after intravenous amiodarone. ${ }^{78}$ The mechanism of acute or chronic amiodarone hepatotoxicity is not known. There have been reports of both cytotoxic and cholestatic liver damage induced by amiodarone. It has been suggested that steatosis and alterations resembling alcoholic hepatitis or cholestatic hepatitis may represent short term side effects with oral treatment, whereas micronodular cirrhosis may be a long term side effect. ${ }^{9}$

The pattern of abnormalities in our patients is typical of hepatitis. Severe acute hepatic dysfunction with intravenous amiodarone is rarely reported and our two cases suggest that the liver is more susceptible to amiodarone toxicity when it is haemodynamically compromised or hypoxic.

Amiodarone is a popular antiarrhythmic agent because of its high efficacy in otherwise resistant arrhythmias and its freedom from any negative inotropic effects. In view of its widespread use, both intravenous and oral, it is important to be aware of any serious adverse reactions. We have reported these two cases to the Committee on the Safety of Medicines.

\section{References}

1 Harris L, McKenna WJ, Rowland E, Holt DW, Storey GCA, Krikler DM. Side effects of longterm amiodarone therapy. Circulation 1983;67:45-51.

2 Fogoros RN, Anderson KP, Winkle RA, Swerdlow $\mathrm{CD}$, Mason JW. Amiodarone: clinical efficacy and toxicity in 96 patients with recurrent drug refractory arrhythmias. Circulation 1983;68:88-94.

3 Heger JJ, Prystowsky EN, Jackman WM, et al. Amiodarone: clinical efficacy and electrophysiology during longterm therapy for recurrent ventricular tachycardia or ventricular fibrillation $N$ Engl $J$ Med 1981;305:539-45.

4 McGovern B, Garan H, Kelly E, Ruskin JN. Adverse reactions during treatment with amiodarone hydrochloride. $\mathrm{Br}$ Med J 1983;287:175-80.

5 Plonteux G, Heaghem C, Ernowald H, Vandeghen N. Longterm hepatic tolerance of amiodarone in the clinic. Eur J Pharmacol 1969;8:369-76.

6 McGovern B, Garan H, Kelly E, Ruskin JN. Adverse reactions during treatment with amiodarone hydrochloride. $\mathrm{Br} \mathrm{Med} J$ 1983;287:175-80.

7 Lupon-Roses J, Simo-Canonge R, Lu Cortez L, Permanyer-Miralda G, Allende-Monclus H. Probable early acute hepatitis with parenteral amiodarone. Clin Cardiol 1986;9:223-9.

8 Yagupsky P, Gazala E, Sofa S, Maor E, Abarbanel J. Fatal hepatic failure and encephalopathy associated with amiodarone therapy. J Pediatr 1985;107:967-70.

9 Rumessen JJ. Hepatotoxicity of amiodarone. Acta Med Scand 1986;219:235-9. 